\title{
Decision Making: Intra-arterial Therapies for Cholangiocarcinoma-TACE and TARE
}

\author{
Brian M. Currie, MD ${ }^{1}$ Michael C. Soulen, MD, FSIR, FCIRSE ${ }^{1}$ \\ ${ }^{1}$ Department of Radiology, Hospital of the University of Pennsylvania, \\ Philadelphia, Pennsylvania \\ Address for correspondence Michael C. Soulen, MD, FSIR, FCIRSE, \\ Department of Radiology, Hospital of the University of Pennsylvania, \\ 1 Silverstein, 3400 Spruce Street, Philadelphia, PA 19104 \\ Semin Intervent Radiol 2017;34:92-100. \\ (e-mail: Michael.Soulen@uphs.upenn.edu).
}

\author{
Abstract \\ Keywords \\ - intrahepatic \\ cholangiocarcinoma \\ - locoregional therapy \\ - transarterial \\ chemoembolization \\ - transarterial \\ radioembolization \\ - interventional \\ radiology
}

The incidence of intrahepatic cholangiocarcinoma (ICC) has been increasing in recent years and now represents the second most common primary hepatic cancer in the United States. The prognosis is dismal without surgical resection. In patients ineligible to receive curative treatments, locoregional therapies represent a diverse array of techniques that can stabilize or reverse tumor progression to improve overall survival and reduce tumor-related symptoms. Transarterial chemoembolization (TACE) and transarterial radioembolization (TARE) have been demonstrated to be efficacious methods for this patient population. Deciding between these two options is challenging. This article reviews the differences in patient selection, preprocedural evaluation, financial considerations and availability, quality of life, and rates of complications and overall survival.
Objectives: Upon completion of this article, the reader will be able to discuss how to determine the most appropriate therapy, TACE or TARE, in patients with intrahepatic cholangiocarcinoma who are no longer candidates for curative treatment.

Accreditation: This activity has been planned and implemented in accordance with the Essential Areas and Policies of the Accreditation Council for Continuing Medical Education (ACCME) through the joint providership of Tufts University School of Medicine (TUSM) and Thieme Medical Publishers, New York. TUSM is accredited by the ACCME to provide continuing medical education for physicians.

Credit: Tufts University School of Medicine designates this journal-based CME activity for a maximum of $1 \boldsymbol{A M A}$ PRA Category 1 Credit $^{\mathrm{TM}}$. Physicians should claim only the credit commensurate with the extent of their participation in the activity.

Intrahepatic cholangiocarcinoma (ICC) is a rare but devastating disease. Owing to the underlying clinical latency and advanced stage at diagnosis, it has an exceedingly poor prognosis. The only curative option is ablation or surgical resection, but only 15 to $30 \%$ of ICCs are resectable. ${ }^{1-3}$ ICC has a particularly grim prognosis when unresectable; if treatment is not pursued, patients have a median overall survival (OS) of 3 months. ${ }^{4}$

ICC is a gland-forming neoplasm that has been associated with two different precursor lesions-either a microscopic papillary or flat dysplastic epithelium, or a macroscopic papillary growth (biliary intraductal papillary neoplasm) that is closely related to the well-known pancreatic intraductal papillary mucinous neoplasm (IPMN). 5,6 There are three imaging phenotypes: mass forming type (most common, characterized by a definite round-shaped mass), periductal infiltration type (identified by longitudinal growth along the bile duct), and intraductal growth type (proliferates toward the lumen of the bile duct). ${ }^{7-10}$ The most common presenting symptoms are abdominal pain (38\%), jaundice secondary to biliary obstruction (28\%), and increased LFTs (11\%), but many times these malignancies are incidentally discovered on imaging. ${ }^{2}$

When ICC demonstrates classical imaging findings on ultrasound, computed tomography (CT), or magnetic resonance (MR), it can be relatively easy to diagnose. However, it often mimics a host of malignant and benign conditions, and even these "classical" findings are associated with an array of pitfalls. ${ }^{11}$ Positron emission tomography (PET) is also used in
Issue Theme Decision Making as a Growth Mechanism in Interventional Oncology; Guest Editor, Daniel B. Brown, $M D, F S I R$
Copyright $\odot 2017$ by Thieme Medical Publishers, Inc., 333 Seventh Avenue, New York, NY 10001, USA. Tel: +1(212) 584-4662.
DOI https://doi.org/ 10.1055/s-0037-1602591. ISSN 0739-9529. 
the evaluation and staging of ICC, possessing equal sensitivity and higher specificity when compared with CT for evaluation of lymph node involvement. ${ }^{9,12,13}$

Screening is uncommon as most cholangiocarcinomas occur de novo without any identifiable risk factors, and providers do not have a high level of suspicion for these patients. ${ }^{14}$ Known risk factors include any processes that induce chronic inflammation or cholestasis in the biliary duct. These include primary sclerosing cholangitis, liver fluke infection (Clonorchis sinensis or Opisthorchis viverrini), congenital fibropolycystic liver disease, hepatolithiasis, and thorotrast exposure. ${ }^{15}$ One population-based case-control study has described other risk factors associated with cholangiocarcinomas, including alcoholic liver disease, diabetes, chronic pancreatitis, and nonspecific cirrhosis. Delving further, it also identified conditions specific to ICC, such as hepatitis $\mathrm{C}$ virus (HCV), obesity, smoking, and nonalcoholic liver disease-all of which are associated with HCV. ${ }^{16}$ As the rates of the HCV and ICC have been increasing in tandem in the United States, these commonalities could offer a harmonious explanation. ${ }^{17}$ Indeed, it has been suggested that these malignancies may have a common origin due to carcinogenesis of progenitor cells in the liver. ${ }^{18}$

From 1975 to 1999 , there was a $165 \%$ increase in the ageadjusted incidence rates of ICC. Among people older than 65 years, there was a fivefold increase in Asians compared with a threefold increase in older whites. ${ }^{19}$ It is the second most common primary hepatic cancer, representing $19.2 \%$ of all cases in the United States, and 3\% of all gastrointestinal malignancies worldwide. ${ }^{15,20,21}$

The majority of this ballooning in the incidence rate occurred after 1985, which closely tracks the increase in hepatic transplantation that occurred between 1982 and 1997. It has been suggested that the rigorous preoperative evaluation has led to an increase in incidentally identified tumors. ${ }^{22}$ However, Khan et al have demonstrated that this rise is not associated with increased detection of early-stage disease, as the rate has not leveled off as would be expected if due primarily to improved diagnostics. The heterogeneity of this increase, affecting different genders, ethnic groups, and even geographic regions, lends credence to the argument that this phenomenon is legitimate. ${ }^{15}$ Furthermore, the increased incidence is not due to the more recent reclassification of Klatskin tumors to prevent ICD cross referencing with ICC. Even after exclusion of misclassification of Klatskin tumors, the rate is still increasing. ${ }^{23}$ One partial explanation could be improvement in immunohistochemical diagnosis, with more tumors being identified as cholangiocarcinoma rather than adenocarcinoma of unknown primary.

To supplement the imaging findings and clinical history, the initial evaluation should also include biochemical tests, namely, CEA, CA 19-9, and AFP, with CA19-9 being the most informative. ${ }^{24}$ A CA $19-9$ of greater than $100 \mathrm{U} / \mathrm{mL}$ was associated with a diagnostic sensitivity of $53 \%$, and a level higher than $129 \mathrm{U} / \mathrm{mL}$ is $79 \%$ sensitive and $98 \%$ specific. $^{9}$ Patients with unresectable cholangiocarcinoma had much higher levels of CA 19-9 compared with those with resectable disease, with a mean of 15,653 and 344 , respectively. ${ }^{25}$
Once the diagnosis is made, the staging of the tumor becomes critical as the treatment algorithm diverges widely based on this information. Although there are several proposed staging systems, the seventh and most recent edition of AJCC appears to be the most discerning in regard to OS and prognosis. Tumor size is not a factor; the essential components are tumor number, vascular invasion, and metastases, all aspects that have been shown to directly correlate with OS. ${ }^{26-28}$

\section{Curative Therapies}

\section{Resection}

For patients with ICC, surgical resection remains the only true curative option. Very few patients are eligible for resection upon presentation. The general philosophy regarding surgery entails selecting patients who have solitary lesions that with resection would leave behind a minimum of two contiguous liver segments with adequate perfusion, and venous and biliary drainage. There is some latitude with these criteria and certain patients with multifocal tumors in close proximity or with limited metastases to the porta hepatic lymph nodes can also be considered. ${ }^{5}$ This translates into the following exclusion criteria: multifocal hepatic disease (generally), lymph nodes metastases beyond the porta hepatitis, and distant metastases. ${ }^{29}$

Even in carefully selected patients, the literature is mixed regarding the efficacy and OS. A review by Ohtsuka et al found a median OS of 25.5 months, while Endo et al reported a disease-specific survival of 36 months, although OSs as low as 12.8 months have been reported. ${ }^{5,30,31}$ In that same study by Endo et al, it was found that $62 \%$ of patients recurred at a median interval of 26 months, compared with another study by Weber et al where $61 \%$ of patients recurred at 12.4 months. $^{2}$ In practical terms, surgery changes the 5-year survival rate from roughly $10 \%$ to $20-40 \% .^{32}$ Factors associated with decreased OS are older age, a larger or poorly differentiated tumor, multiple tumors, liver capsule or vascular invasion, positive resection margin, and CA 19-9 level higher than $1,000 \mathrm{U} / \mathrm{mL}^{2,28,30}$

Fortunately, it appears that the results from surgery are trending in a positive direction. One study of the SEER database showed that 5-year survival from 1973 to 1992 was $16.5 \%$ and increased to $23 \%$ from 1993 to 2002 . $^{33}$

\section{Transplantation}

Transplantation for ICC has fallen out of favor in recent years due to poor long-term survival. ${ }^{34}$ Although the literature is mixed, one study reported a dismal median survival time of 5 months (compared with 12.8 months for resection) and a 1-year survival rate of $13.9 \% .^{31}$ Even after transplantation, recurrence is fairly common and occurs in as many as 54\% of patients. $^{35,36}$

De Vreede et al demonstrated promising results in highly selected patients with early-stage disease who had received aggressive preoperative chemoradiation-external beam, brachytherapy, and bolus fluorouracil (FU) followed by continuous hepatic arterial infusion with FU until transplantation. ${ }^{37}$ 


\section{Radiation}

Despite early studies showing the benefits of external beam radiotherapy, its use remains contentious. ${ }^{38-40}$ As conventional doses of radiation were too low for disease control and targeting was less refined, it was difficult to selectively target the malignancy and spare the surrounding parenchyma at the necessary doses. However, recent advances in technique have allowed for substantially increased doses with improved accuracy.

In one recent retrospective analysis, patients were definitively treated with intensity-modulated radiation therapy resulting in an OS of 30 months, with total radiation dose being the best predictor of outcome-well within the range of survival seen for surgical resection. Of note and potentially confounding these results, this was a patient population receiving numerous therapies, with $89 \%$ previously completing a chemotherapy regimen. ${ }^{41}$

\section{Noncurative Therapies}

\section{Chemotherapy}

As most patients present with advanced stage disease and are not candidates for surgical therapy, the majority of patients will receive systemic chemotherapy to prolong life. Other than surgery, chemotherapy is the only category 1 therapy in the NCCN guidelines for ICC, despite the marginal benefits that are derived from this option and the fact that many of the trials evaluating chemotherapy have heterogeneous populations of biliary tract cancers, with some even including pancreatic malignancies. ${ }^{29}$

A recent meta-analysis of large randomized clinical trials of mixed patients-extra- and intrahepatic cholangiocarcinoma, gallbladder, and ampullary-showed that combination cisplatin and gemcitabine improved median OS to 11.6 months compared with 8 months with gemcitabine alone. ${ }^{42-45}$ This outcome is in comparison to the natural course of the disease with a median survival of 3 months.

\section{Locoregional Therapy}

In clinical situations that preclude resection or definitive radiation, locoregional therapies can be employed to halt disease progression and prolong life, or as a bridge to curative treatments (e.g., downstaging unresectable tumors). ${ }^{46-48}$ In these patients, the major cause of mortality is related to local progression to liver failure or biliary complications-an assertion supported by the similar survival of patients with extrahepatic metastases. ${ }^{26,49}$ The use of these therapies, alone or in combination, has been shown to improve OS. $^{50}$ There is a wide array of techniques that can be utilized for this strategy, all with varying advantages and disadvantages. Determining the ideal procedure for a given clinical scenario has become an active area of research and is the primary objective of this discussion.

\section{Ablation}

There is growing body of literature detailing the efficacy of thermal ablation in attaining local control of ICC (-Fig. 1). One retrospective study of patients ineligible for surgery demonstrated a median OS of 33 months and a 5-year survival of $29 \%{ }^{51}$ A prospective study comparing repeat resection to thermal ablation in recurrent ICC showed no difference in OS between the two groups when performed in tumors less than $3 \mathrm{~cm} .{ }^{52}$ Another prospective study showed an OS after ablation of recurrent disease to be $30.3 \%$ at 5 years, and $62.5 \%$ when treating primary disease. ${ }^{53}$ Ablation is listed with surgery in the NCCN guidelines for resectable ICC.

\section{Arterial-Based Therapies}

There is a substantial body of research validating the use of transarterial therapies in patients with a host of unresectable hepatic malignancies, both primary and secondary, for the purposes of locoregional control. ${ }^{54-64}$ Owing to the rarity of ICC, the majority of studies investigating arterialbased therapies are small retrospective analyses that lack the power to generate definitive recommendations. Although these studies are promising, the NCCN guidelines still consider locoregional techniques in ICC to be Category 2 B. $^{29,32,65-78}$

For the purposes of this discussion, both bland embolization and hepatic artery infusion (a continuous infusion of chemotherapy through the hepatic artery via a surgically implanted device) will only be elaborated upon indirectly. The focus will be choosing between chemoembolization and radioembolization.

\section{Transarterial Chemoembolization}

Compared with symptomatic management, conventional lipiodol-based chemoembolization (cTACE) has been demonstrated to improve survival from a median of 3.3 to 12.2 months. ${ }^{68}$ Surprisingly, Scheuermann et al found there was no survival difference between surgical patients with positive resection margins (11 months) or lymph nodepositive disease (9 months) and patients with unresectable disease receiving CTACE or DEB-TACE (11 months). ${ }^{72}$

There is significant variability in the literature regarding the efficacy of TACE, which is a consequence of small retrospective studies representing the preponderance of published data. In a relatively large U.S. multicenter series, 62 patients receiving the most common chemoembolization regimen of mitomycin C, doxorubicin, and cisplatin had a median OS of 15 months from the initiation of CTACE and 20 months from the initial diagnosis, with a median time to progression of 8 months. When systemic chemotherapy was added to CTACE, median OS increased to 28 months. ${ }^{26}$ Ten percent had partial response and $66 \%$ showed disease stability based on RECIST criteria. These results are in stark contrast to the study by Kuhlmann et al which demonstrated an OS of 5.7 months and a progression-free survival (PFS) of only 1.8 months with single-agent cTACE; this study also reported an OS of 11.7 months and PFS of 3.9 months for DEB-TACE. ${ }^{79}$

A meta-analysis of chemotherapy-based transarterial therapies was recently performed by Ray et al. ${ }^{80}$ This group found a weighted cumulative median OS from date of diagnosis to be 15.7 months, and 13.4 from the first TACE treatment. Despite the limitations of this study, which was 

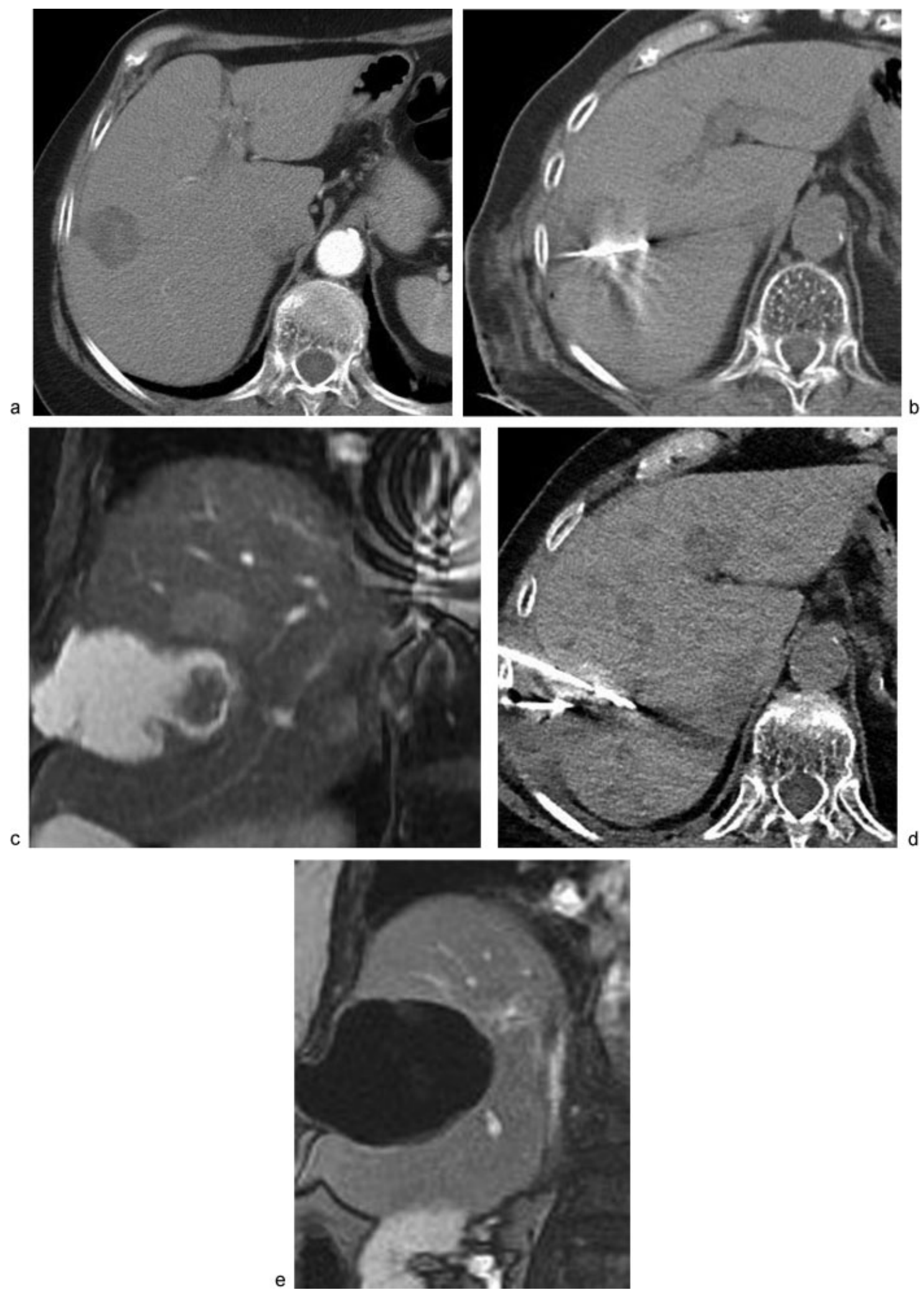

Fig. 1 Long-term control of intrahepatic cholangiocarcinoma (ICC) with serial ablation. (a) Initial presentation with 3-cm ICC, treated with radiofrequency ablation in 2010. (b) Marginal recurrence in 2013 treated with microwave ablation. (c) Superior marginal recurrence (thin arrow) above ablation cavity with "ghost" of original lesion (thick arrow). (d) Re-treatment with microwave ablation. (e) Latest imaging in 2016 shows avascular ablation cavity and no new lesions. 
challenged by nonuniform reporting of data and studies using a wide variety of chemotherapies and sometimes not even an embolic agent, these results serve as a reasonable benchmark for the efficacy and safety of TACE in the absence of randomized controlled trials (-Fig. 2 ).

\section{Radioembolization}

The primary indication for radioembolization with yttrium90 microspheres is for unresectable ICC who have a life expectancy of greater than 3 months. ${ }^{81}$ There are also data now supporting its use for downstaging unresectable ICC to allow for secondary resection, an indication previously validated for patients with $\mathrm{HCC}^{48,77,82}$

Numerous studies have demonstrated that radioembolization can be used effectively in carefully selected patients with ICC. ${ }^{74-77}$ Factors portending a worse prognosis in these patients are multifocal, infiltrative, or bilobar disease. ${ }^{77,83}$ As with TACE, the literature is varied in regard to tumor response and OS due to the majority of data being derived from small retrospective/prospective cohort studies. Nonetheless, the results are promising.

A study by Hoffmann et al demonstrated an OS from first treatment of 22 months in patients who previously received multiple therapies (surgery, radiation, chemotherapy, previously locoregional techniques) with a time from diagnosis to RE of 21.2 months. Using the RECIST criteria, $36.4 \%$ had a partial response and $51.5 \%$ had stable disease. ${ }^{75}$ This is contrasted with the study by Rafi et al which showed a median survival from first treatment of 11.5 months and a poorer tumor response ( $11 \%$ with a partial response and $68 \%$ with disease stability). ${ }^{84}$ However, the patients selected for this study were chemorefractory and presumably had more treatment-resistant disease.

To combat the heterogeneity of these smaller studies, a systematic review was performed by Al-Adra et al and revealed an overall weighted medial survival of 15.5 months, with a partial response and stable disease rates of 28 and $54 \%$, respectively. ${ }^{85}$ Again, despite the limitations of this study, it serves as a reasonable barometer for the impact of Y-90 therapy on OS and tumor response.

\section{Chemoembolization versus Radioembolization}

The similar rates of OS and tumor response argue against a clinically significant difference between TARE and TACE for ICC. Multiple groups have conducted reviews of the current studies and a similar conclusion has been drawn: that determining the most efficacious methods amongst Y-90 and TACE is not possible based on the available data. ${ }^{49,83,86}$ Even with systematic reviews and pooled analyses to increase power, the primary studies are too heterogeneous to discern a genuine difference. One systematic review by Yang et al showed a median OS of 12.5 months for RE and 13 months for TACE. ${ }^{83}$ Another by Boehm et al revealed a survival of 12.4 months for cTACE, 12.3 months for DEB-TACE, and 13.9 months for Y-90-a complete or partial tumor response was seen in $17.3 \%$ of cTACE and $27.4 \%$ of Y90 cases. ${ }^{86}$ Furthermore, rates of adverse events are not substantially different between the two techniques, with only a statistically insignificant trend suggesting that TACE may incur more toxicities of Grade 3 or greater. ${ }^{49}$ A team from Johannes Gutenberg University Mainz in Germany is conducting a randomized clinical trial comparing DEB-TACE and radioembolization with SIR-Spheres. ${ }^{87}$ The study is currently recruiting patients, and the primary outcome measure will be PFS.

Until a randomized control trial is performed, the decision about which technique to use will be determined by patientspecific factors. Prior biliary intervention such as bilioenteric anastomosis, stent, or sphincterotomy is a relative contraindication to TACE because of the risk of liver abscess. Infectious complications after TARE are rare in this setting, making it the preferred technique. ${ }^{88}$ Another relevant issue is the short-term toxicity of TACE from postembolization syndrome. Patients who are frail or caretakers for a family member, or who are employed full-time may prefer TARE to minimize disruptive side effects and preserve short-term quality of life. Conversely, some patients are not comfortable
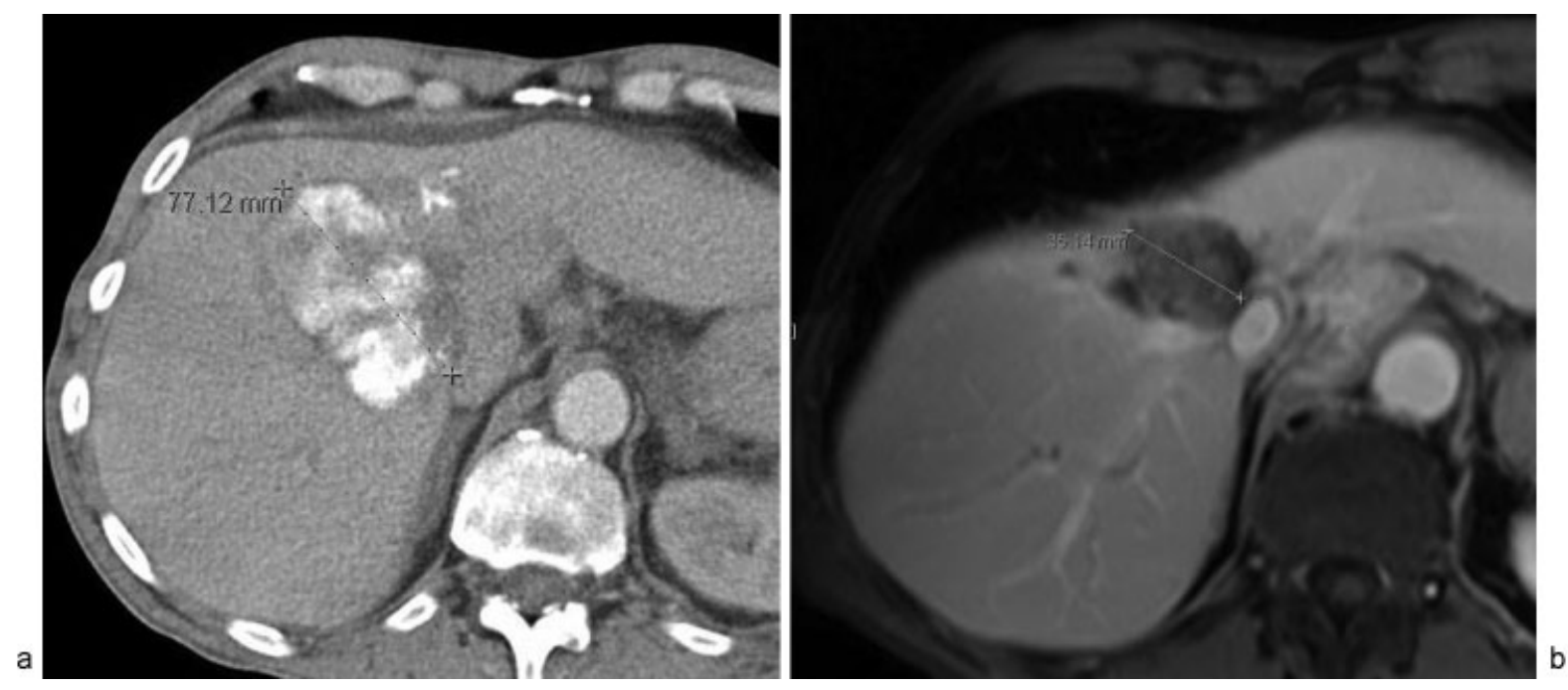

Fig. 2 Chemoembolization of intrahepatic cholangiocarcinoma (ICC). (a) CT 1 month after transarterial chemoembolization shows dense lipiodol retention in a 7.7-cm ICC. (b) MRI at 30-month follow-up shows no residual enhancement and a $50 \%$ reduction in tumor diameter. 


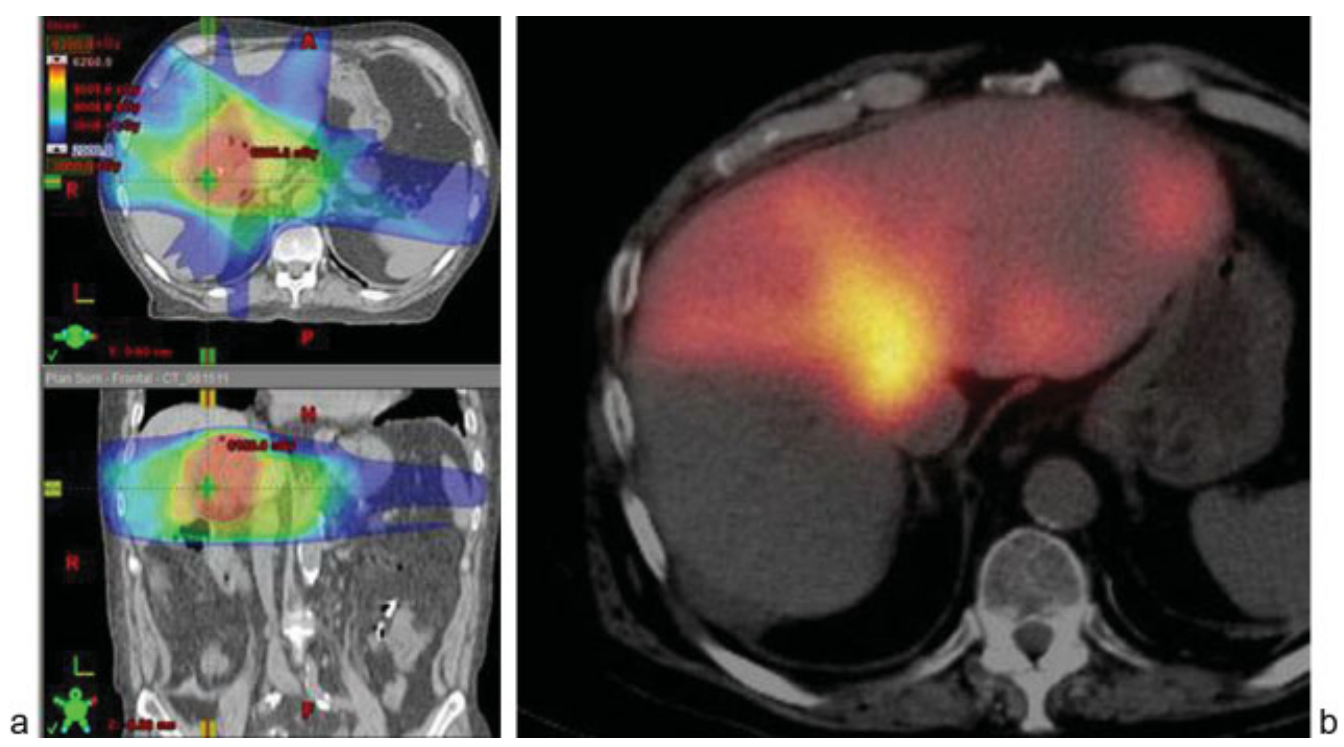

Fig. 3 Dosimetry images for external beam radiotherapy and transarterial radioembolization (TARE). The two sets of images were reviewed at matched levels to determine if radioembolization would be safe. (a) Dosimetry plot for prior hilar radiation field. (b) Image from TARE simulation using intra-arterial Tc-99m macro-aggregated albumin for a caudate lobe recurrence.

with the longer time to treatment and 3-month delay in response assessment inherent to TARE, and are willing to endure the toxicity of TACE to have treatment and assessment of response more promptly. Severity of postembolization syndrome must be considered when concurrent systemic chemotherapy is planned. Not all patients can tolerate the combined side effects of TACE and gemcitabine/cisplatin, requiring sequencing of therapy and good communication with the medical oncologist. The synergy between these chemotherapeutics and radiation makes combination with TARE appealing, although any benefit from the combination has not been evaluated prospectively.

Some ICC patients will have been treated previously with hepatic SBRT or EBRT to the hilum or portal fields. While TACE can be performed safely in this circumstance, TARE must be planned very carefully to avoid radiation toxicity to the liver. It is critical to line up the fusion images from the Tc99m-MAA-SPECT TARE simulation with the dosimetry plot from the prior radiation therapy to be sure that the Y90 activity does not overlap the previously radiated liver volume (-Fig. 3).

Accessibility and the ability to properly utilize these resources may be a deciding factor in which therapy to choose. Since its inception in the early 1980s, TACE has become a commonly used and widely available treatment modality. ${ }^{89}$ TARE, however, is a more recently validated technique, is more technically challenging, and demands a significant commitment from a multidisciplinary team that includes radiation oncology, nuclear medicine, medical physics, hepatology, medical oncology, and radiation safety. ${ }^{81}$ As such, its availability outside of large academic centers is limited. This larger team and more involved preprocedural planning also results in a higher financial cost for TARE, roughly two times the cost of TACE. ${ }^{90}$

\section{References}

1 Hong K, Geschwind JF. Locoregional intra-arterial therapies for unresectable intrahepatic cholangiocarcinoma. Semin Oncol 2010;37(02):110-117

2 Weber SM, Jarnagin WR, Klimstra D, DeMatteo RP, Fong Y, Blumgart LH. Intrahepatic cholangiocarcinoma: resectability, recurrence pattern, and outcomes. J Am Coll Surg 2001;193(04): 384-391

3 Tan JC, Coburn NG, Baxter NN, Kiss A, Law CH. Surgical management of intrahepatic cholangiocarcinoma-a population-based study. Ann Surg Oncol 2008;15(02):600-608

4 Park J, Kim MH, Kim KP, et al. Natural history and prognostic factors of advanced cholangiocarcinoma without surgery, chemotherapy, or radiotherapy: a large-scale observational study. Gut Liver 2009;3(04):298-305

5 Endo I, Gonen M, Yopp AC, et al. Intrahepatic cholangiocarcinoma: rising frequency, improved survival, and determinants of outcome after resection. Ann Surg 2008;248(01):84-96

6 Zen Y, Adsay NV, Bardadin K, et al. Biliary intraepithelial neoplasia: an international interobserver agreement study and proposal for diagnostic criteria. Mod Pathol 2007;20(06):701-709

7 Maithel SK, Gamblin TC, Kamel I, Corona-Villalobos CP, Thomas M, Pawlik TM. Multidisciplinary approaches to intrahepatic cholangiocarcinoma. Cancer 2013;119(22):3929-3942

8 Yamasaki S. Intrahepatic cholangiocarcinoma: macroscopic type and stage classification. J Hepatobiliary Pancreat Surg 2003; 10(04):288-291

9 Yang J, Yan LN. Current status of intrahepatic cholangiocarcinoma. World J Gastroenterol 2008;14(41):6289-6297

10 Isaji S, Kawarada Y, Taoka H, Tabata M, Suzuki H, Yokoi H. Clinicopathological features and outcome of hepatic resection for intrahepatic cholangiocarcinoma in Japan. J Hepatobiliary Pancreat Surg 1999;6(02):108-116

11 Chung YE, Kim MJ, Park YN, et al. Varying appearances of cholangiocarcinoma: radiologic-pathologic correlation. Radiographics 2009;29(03):683-700

12 Kim Y-J, Yun M, Lee WJ, Kim KS, Lee JD. Usefulness of 18F-FDG PET in intrahepatic cholangiocarcinoma. Eur J Nucl Med Mol Imaging 2003;30(11):1467-1472 
13 Grobmyer SR, Wang L, Gonen M, et al. Perihepatic lymph node assessment in patients undergoing partial hepatectomy for malignancy. Ann Surg 2006;244(02):260-264

14 Razumilava N, Gores GJ. Cholangiocarcinoma. Lancet 2014; 383(9935):2168-2179

15 Khan SA, Toledano MB, Taylor-Robinson SD. Epidemiology, risk factors, and pathogenesis of cholangiocarcinoma. HPB (Oxford) 2008;10(02):77-82

16 Welzel TM, Graubard BI, El-Serag HB, et al. Risk factors for intrahepatic and extrahepatic cholangiocarcinoma in the United States: a population-based case-control study. Clin Gastroenterol Hepatol 2007;5(10):1221-1228

17 McGlynn KA, Tarone RE, El-Serag HB. A comparison of trends in the incidence of hepatocellular carcinoma and intrahepatic cholangiocarcinoma in the United States. Cancer Epidemiol Biomarkers Prev 2006;15(06):1198-1203

18 Roskams T. Liver stem cells and their implication in hepatocellular and cholangiocarcinoma. Oncogene 2006;25(27):3818-3822

19 Shaib YH, Davila JA, McGlynn K, El-Serag HB. Rising incidence of intrahepatic cholangiocarcinoma in the United States: a true increase? J Hepatol 2004;40(03):472-477

20 de Groen PC, Gores GJ, LaRusso NF, Gunderson LL, Nagorney DM. Biliary tract cancers. N Engl J Med 1999;341(18):1368-1378

21 Surveillance, Epidemiology, and End Results (SEER) Program Populations (1969-2014). National Cancer Institute, DCCPS, Surveillance Research Program, Surveillance Systems Branch, released March 2016. Available at: www.seer.cancer.gov/popdata. Accessed April 12, 2017

22 Patel T. Increasing incidence and mortality of primary intrahepatic cholangiocarcinoma in the United States. Hepatology 2001; 33(06):1353-1357

23 Welzel TM, McGlynn KA, Hsing AW, O’Brien TR, Pfeiffer RM. Impact of classification of hilar cholangiocarcinomas (Klatskin tumors) on the incidence of intra- and extrahepatic cholangiocarcinoma in the United States. J Natl Cancer Inst 2006;98(12): 873-875

24 Poultsides GA, Zhu AX, Choti MA, Pawlik TM. Intrahepatic cholangiocarcinoma. Surg Clin North Am 2010;90(04):817-837

25 Patel AH, Harnois DM, Klee GG, LaRusso NF, Gores GJ. The utility of CA 19-9 in the diagnoses of cholangiocarcinoma in patients without primary sclerosing cholangitis. Am J Gastroenterol 2000; 95(01):204-207

26 Kiefer MV, Albert M, McNally M, et al. Chemoembolization of intrahepatic cholangiocarcinoma with cisplatinum, doxorubicin, mitomycin C, Ethiodol, and polyvinyl alcohol: a 2-center study. Cancer 2011;117(07):1498-1505

27 Farges O, Fuks D, Le Treut Y-P, et al. AJCC 7th edition of TNM staging accurately discriminates outcomes of patients with resectable intrahepatic cholangiocarcinoma: by the AFC-IHCC-2009 study group. Cancer 2011;117(10):2170-2177

28 Mavros MN, Economopoulos KP, Alexiou VG, Pawlik TM. Treatment and prognosis for patients with intrahepatic cholangiocarcinoma: systematic review and meta-analysis. JAMA Surg 2014; 149(06):565-574

29 National Comprehensive Cancer Network. Hepatobiliary Cancers (Version 2.2016). Available at: https://www.nccn.org/professionals/ physician_gls/PDF/hepatobiliary.pdf. Accessed August 31, 2016

30 Ohtsuka M, Ito H, Kimura F, et al. Results of surgical treatment for intrahepatic cholangiocarcinoma and clinicopathological factors influencing survival. Br J Surg 2002;89(12):1525-1531

31 Pichlmayr R, Lamesch P, Weimann A, Tusch G, Ringe B. Surgical treatment of cholangiocellular carcinoma. World J Surg 1995; 19(01):83-88

32 Simo KA, Halpin LE, McBrier NM, et al. Multimodality treatment of intrahepatic cholangiocarcinoma: a review. J Surg Oncol 2016; 113(01):62-83

33 Nathan H, Pawlik TM, Wolfgang CL, Choti MA, Cameron JL, Schulick RD. Trends in survival after surgery for cholangiocarcinoma: a 30-year population-based SEER database analysis. J Gastrointest Surg 2007;11(11):1488-1496, discussion 1496-1497

34 Meyer CG, Penn I, James L. Liver transplantation for cholangiocarcinoma: results in 207 patients. Transplantation 2000;69(08): 1633-1637

35 Shimoda M, Farmer DG, Colquhoun SD, et al. Liver transplantation for cholangiocellular carcinoma: analysis of a single-center experience and review of the literature. Liver Transpl 2001; 7(12):1023-1033

36 Fu B-S, Zhang T, Li H, et al. The role of liver transplantation for intrahepatic cholangiocarcinoma: a single-center experience. Eur Surg Res 2011;47(04):218-221

37 De Vreede I, Steers JL, Burch PA, et al. Prolonged disease-free survival after orthotopic liver transplantation plus adjuvant chemoirradiation for cholangiocarcinoma. Liver Transpl 2000; 6(03):309-316

38 Shinohara ET, Mitra N, Guo M, Metz JM. Radiation therapy is associated with improved survival in the adjuvant and definitive treatment of intrahepatic cholangiocarcinoma. Int J Radiat Oncol Biol Phys 2008;72(05):1495-1501

39 Dawson LA, McGinn CJ, Normolle D, et al. Escalated focal liver radiation and concurrent hepatic artery fluorodeoxyuridine for unresectable intrahepatic malignancies. J Clin Oncol 2000; 18(11):2210-2218

40 Jirtle RL, Anscher MS, Alati T. Radiation sensitivity of the liver. In: Altman KI, Lett JT, ed. Advances in Radiation Biology: Relative Radiation Sensitivities of Human Organ Systems, Part IV. Vol 14. San Diego, CA: Academic Press; 1990:269-311

41 Tao R, Krishnan S, Bhosale PR, et al. Ablative radiotherapy doses lead to a substantial prolongation of survival in patients with inoperable intrahepatic cholangiocarcinoma: a retrospective dose response analysis. J Clin Oncol 2016;34(03): 219-226

42 Valle JW, Furuse J, Jitlal M, et al. Cisplatin and gemcitabine for advanced biliary tract cancer: a meta-analysis of two randomised trials. Ann Oncol 2014;25(02):391-398

43 Valle J, Wasan H, Palmer DH, et al; ABC-02 Trial Investigators. Cisplatin plus gemcitabine versus gemcitabine for biliary tract cancer. N Engl J Med 2010;362(14):1273-1281

44 Eckel F, Schmid RM. Chemotherapy in advanced biliary tract carcinoma: a pooled analysis of clinical trials. Br J Cancer 2007; 96(06):896-902

45 Okusaka T, Nakachi K, Fukutomi A, et al. Gemcitabine alone or in combination with cisplatin in patients with biliary tract cancer: a comparative multicentre study in Japan. Br J Cancer 2010; 103(04):469-474

46 Llovet JM, Bruix J. Systematic review of randomized trials for unresectable hepatocellular carcinoma: chemoembolization improves survival. Hepatology 2003;37(02):429-442

47 Chua TC, Liauw W, Saxena A, et al. Systematic review of neoadjuvant transarterial chemoembolization for resectable hepatocellular carcinoma. Liver Int 2010;30(02):166-174

48 Rayar M, Sulpice L, Edeline J, et al. Intra-arterial yttrium-90 radioembolization combined with systemic chemotherapy is a promising method for downstaging unresectable huge intrahepatic cholangiocarcinoma to surgical treatment. Ann Surg Oncol 2015;22(09):3102-3108

49 Seidensticker R, Ricke J, Seidensticker M. Integration of chemoembolization and radioembolization into multimodal treatment of cholangiocarcinoma. Best Pract Res Clin Gastroenterol 2015;29(02):319-332

50 Seidensticker R, Seidensticker M, Doegen K, et al. Extensive use of interventional therapies improves survival in unresectable or recurrent intrahepatic cholangiocarcinoma. Gastroenterol Res Pract 2016;2016:8732521

51 Fu Y, Yang W, Wu W, Yan K, Xing BC, Chen MH. Radiofrequency ablation in the management of unresectable intrahepatic cholangiocarcinoma. J Vasc Interv Radiol 2012;23(05):642-649 
52 Zhang S-J, Hu P, Wang N, et al. Thermal ablation versus repeated hepatic resection for recurrent intrahepatic cholangiocarcinoma. Ann Surg Oncol 2013;20(11):3596-3602

53 Xu HX, Wang Y, Lu MD, Liu LN. Percutaneous ultrasound-guided thermal ablation for intrahepatic cholangiocarcinoma. Br J Radiol 2012;85(1016):1078-1084

54 Lo CM, Ngan H, Tso WK, et al. Randomized controlled trial of transarterial lipiodol chemoembolization for unresectable hepatocellular carcinoma. Hepatology 2002;35(05):1164-1171

55 Llovet JM, Real MI, Montaña X, et al; Barcelona Liver Cancer Group. Arterial embolisation or chemoembolisation versus symptomatic treatment in patients with unresectable hepatocellular carcinoma: a randomised controlled trial. Lancet 2002;359(9319): 1734-1739

56 Marelli L, Stigliano R, Triantos C, et al. Transarterial therapy for hepatocellular carcinoma: which technique is more effective? A systematic review of cohort and randomized studies. Cardiovasc Intervent Radiol 2007;30(01):6-25

57 Gupta S, Johnson MM, Murthy R, et al. Hepatic arterial embolization and chemoembolization for the treatment of patients with metastatic neuroendocrine tumors: variables affecting response rates and survival. Cancer 2005;104(08):1590-1602

58 Salem R, Lewandowski RJ, Kulik L, et al. Radioembolization results in longer time-to-progression and reduced toxicity compared with chemoembolization in patients with hepatocellular carcinoma. Gastroenterology 2011;140(02):497-507.e2

59 Salem R, Lewandowski RJ, Mulcahy MF, et al. Radioembolization for hepatocellular carcinoma using Yttrium-90 microspheres: a comprehensive report of long-term outcomes. Gastroenterology 2010;138(01):52-64

60 Kennedy A, Coldwell D, Sangro B, Wasan H, Salem R. Integrating radioembolization into the treatment paradigm for metastatic neuroendocrine tumors in the liver. Am J Clin Oncol 2012;35(04): 393-398

61 Kennedy AS, Dezarn WA, McNeillie P, et al. Radioembolization for unresectable neuroendocrine hepatic metastases using resin 90Ymicrospheres: early results in 148 patients. Am J Clin Oncol 2008; 31(03):271-279

62 Ando E, Tanaka M, Yamashita F, et al. Hepatic arterial infusion chemotherapy for advanced hepatocellular carcinoma with portal vein tumor thrombosis: analysis of 48 cases. Cancer 2002;95(03): 588-595

63 Barber FD, Mavligit G, Kurzrock R. Hepatic arterial infusion chemotherapy for metastatic colorectal cancer: a concise overview. Cancer Treat Rev 2004;30(05):425-436

64 Vogl TJ, Zangos S, Eichler K, Yakoub D, Nabil M. Colorectal liver metastases: regional chemotherapy via transarterial chemoembolization (TACE) and hepatic chemoperfusion: an update. Eur Radiol 2007;17(04):1025-1034

65 Kirchhoff T, Zender L, Merkesdal S, et al. Initial experience from a combination of systemic and regional chemotherapy in the treatment of patients with nonresectable cholangiocellular carcinoma in the liver. World J Gastroenterol 2005;11(08): 1091-1095

66 Aliberti C, Benea G, Tilli M, Fiorentini G. Chemoembolization (TACE) of unresectable intrahepatic cholangiocarcinoma with slow-release doxorubicin-eluting beads: preliminary results. Cardiovasc Intervent Radiol 2008;31(05):883-888

67 Vogl TJ, Naguib NN, Nour-Eldin EA, et al. Transarterial chemoembolization in the treatment of patients with unresectable cholangiocarcinoma: results and prognostic factors governing treatment success. Int J Cancer 2012;131(03):733-740

68 Park SY, Kim JH, Yoon HJ, Lee IS, Yoon HK, Kim KP. Transarterial chemoembolization versus supportive therapy in the palliative treatment of unresectable intrahepatic cholangiocarcinoma. Clin Radiol 2011;66(04):322-328
69 Herber S, Otto G, Schneider J, et al. Transarterial chemoembolization (TACE) for inoperable intrahepatic cholangiocarcinoma. Cardiovasc Intervent Radiol 2007;30(06):1156-1165

70 Poggi G, Amatu A, Montagna B, et al. OEM-TACE: a new therapeutic approach in unresectable intrahepatic cholangiocarcinoma. Cardiovasc Intervent Radiol 2009;32(06): $1187-1192$

71 Burger I, Hong K, Schulick R, et al. Transcatheter arterial chemoembolization in unresectable cholangiocarcinoma: initial experience in a single institution. J Vasc Interv Radiol 2005;16(03): 353-361

72 Scheuermann U, Kaths JM, Heise M, et al. Comparison of resection and transarterial chemoembolisation in the treatment of advanced intrahepatic cholangiocarcinoma-a single-center experience. Eur J Surg Oncol 2013;39(06):593-600

73 Gusani NJ, Balaa FK, Steel JL, et al. Treatment of unresectable cholangiocarcinoma with gemcitabine-based transcatheter arterial chemoembolization (TACE): a single-institution experience. J Gastrointest Surg 2008;12(01):129-137

74 Ibrahim SM, Mulcahy MF, Lewandowski RJ, et al. Treatment of unresectable cholangiocarcinoma using yttrium-90 microspheres: results from a pilot study. Cancer 2008;113(08):2119-2128

75 Hoffmann RT, Paprottka PM, Schön A, et al. Transarterial hepatic yttrium-90 radioembolization in patients with unresectable intrahepatic cholangiocarcinoma: factors associated with prolonged survival. Cardiovasc Intervent Radiol 2012;35(01): $105-116$

76 Saxena A, Bester L, Chua TC, Chu FC, Morris DL. Yttrium-90 radiotherapy for unresectable intrahepatic cholangiocarcinoma: a preliminary assessment of this novel treatment option. Ann Surg Oncol 2010;17(02):484-491

77 Mouli S, Memon K, Baker T, et al. Yttrium-90 radioembolization for intrahepatic cholangiocarcinoma: safety, response, and survival analysis. J Vasc Interv Radiol 2013;24(08):1227-1234

78 Hyder O, Marsh JW, Salem R, et al. Intra-arterial therapy for advanced intrahepatic cholangiocarcinoma: a multi-institutional analysis. Ann Surg Oncol 2013;20(12):3779-3786

79 Kuhlmann JB, Euringer W, Spangenberg HC, et al. Treatment of unresectable cholangiocarcinoma: conventional transarterial chemoembolization compared with drug eluting bead-transarterial chemoembolization and systemic chemotherapy. Eur J Gastroenterol Hepatol 2012;24(04):437-443

80 Ray CEJ Jr, Edwards A, Smith MT, et al. Metaanalysis of survival, complications, and imaging response following chemotherapybased transarterial therapy in patients with unresectable intrahepatic cholangiocarcinoma. J Vasc Interv Radiol 2013;24(08): 1218-1226

81 Kennedy A, Nag S, Salem R, et al. Recommendations for radioembolization of hepatic malignancies using yttrium-90 microsphere brachytherapy: a consensus panel report from the radioembolization brachytherapy oncology consortium. Int J Radiat Oncol Biol Phys 2007;68(01):13-23

82 Kulik LM, Atassi B, van Holsbeeck L, et al. Yttrium-90 microspheres (TheraSphere) treatment of unresectable hepatocellular carcinoma: downstaging to resection, RFA and bridge to transplantation. J Surg Oncol 2006;94(07):572-586

83 Yang L, Shan J, Shan L, Saxena A, Bester L, Morris DL. Trans-arterial embolisation therapies for unresectable intrahepatic cholangiocarcinoma: a systematic review. J Gastrointest Oncol 2015;6(05): 570-588

84 Rafi S, Piduru SM, El-Rayes B, et al. Yttrium-90 radioembolization for unresectable standard-chemorefractory intrahepatic cholangiocarcinoma: survival, efficacy, and safety study. Cardiovasc Intervent Radiol 2013;36(02):440-448

85 Al-Adra DP, Gill RS, Axford SJ, Shi X, Kneteman N, Liau SS. Treatment of unresectable intrahepatic cholangiocarcinoma 
with yttrium-90 radioembolization: a systematic review and pooled analysis. Eur J Surg Oncol 2015;41(01):120-127

86 Boehm LM, Jayakrishnan TT, Miura JT, et al. Comparative effectiveness of hepatic artery based therapies for unresectable intrahepatic cholangiocarcinoma. J Surg Oncol 2015;111(02): 213-220

87 Kloeckner R, Ruckes C, Kronfeld K, et al. Selective internal radiotherapy (SIRT) versus transarterial chemoembolization (TACE) for the treatment of intrahepatic cholangiocellular carcinoma (CCC): study protocol for a randomized controlled trial. Trials 2014; $15: 311$
88 Kim W, Clark TW, Baum RA, Soulen MC. Risk factors for liver abscess formation after hepatic chemoembolization. J Vasc Interv Radiol 2001;12(08):965-968

89 Guan Y-S, He Q, Wang M-Q. Transcatheter arterial chemoembolization: history for more than 30 years. ISRN Gastroenterol 2012; 2012:480650

90 Rostambeigi N, Dekarske AS, Austin EE, Golzarian J, Cressman EN. Cost effectiveness of radioembolization compared with conventional transarterial chemoembolization for treatment of hepatocellular carcinoma. J Vasc Interv Radiol 2014;25(07): 1075-1084 